\title{
A Defensoria Pública e Cuidados em uma Relação de Cuidado: Um Estudo de Caso
}

\author{
Marcos Antonio Barbieri Gonçalves \\ Raquel Souza Lobo Guzzo \\ Pontifícia Universidade Católica de Campinas, SP, Brasil. \\ Pontifícia Universidade Católica de Campinas, SP, Brasil.
}

Resumo: A Defensoria Pública ocupa lugar em processos judiciais de destituição do poder familiar atuando majoritariamente em favor dos pais de famílias pobres. O psicólogo na Defensoria que atua em processos judiciais é chamado de assistente técnico. O objetivo do presente artigo é discutir concepções pertinentes à atuação do psicólogo na Defensoria a partir do lugar processual do assistente técnico, especialmente compreendido dentro das políticas públicas que trabalham com famílias necessitadas nos termos da lei. Para tanto, foi feito um estudo de caso com pesquisa documental qualitativa em busca das ações radicais possíveis. Os dados e as ações foram pensados à luz das teorias winnicottianas do desenvolvimento e do conceito de juízes anexos, de Foucault. O discurso dominante na Psicologia mantém a lógica de legislações anteriores ao Estatuto da Criança e do Adolescente, em que se culpabiliza a família pobre em processos de destituição do poder familiar. O assistente técnico figurou como importante ator para a inserção, no sistema de justiça, da compreensão de que um bebê não é um bebê sozinho, mas será sempre acompanhado de seus principais cuidadores, pessoas de quem ele depende e que são sujeitos que pretendem desfrutar de uma sociedade livre. A prática comunitária produziu o efeito de criar soluções para a situação que gerou sofrimento aos membros de uma família. Concluímos que teorias que associam pobreza e incapacidade de cuidar dos filhos funcionam demodo similar aos códigos minoristas anteriores ao Estatuto da Criança e do Adolescente. Palavras-chave: Assistente Técnico Judiciário, Psicologia Crítica, Práticas Comunitárias, Superior Interesse da Criança, Situação Irregular.

\section{The Public Defender in a Care Relationship: a Case Study}

\begin{abstract}
The Public Defender takes place in lawsuits of destitution of the family power acting largely in favor of the parents of poor families. The psychologist at Public Defender that acts in legal proceedings is called technical assistant. The purpose of this article is to discuss pertinent concepts to the psychologist's activities in Public Defender from the procedural place of the technical assistant, especially understood within the public policies that work with needy families in accordance with law. To that end, we made a case study with qualitative documental research searching for possible radical actions. The data and actions were thought in the light of Winnicott's development theories and the concept of attachments judges, by Foucault. The dominant discourse in psychology maintains the logic of previous legislation to the Statute of Children and Adolescents, in which blames the poor family in the family power dismissal processes. The technical assistant figured as an important actor for the inclusion, in the justice system, of the understanding that a baby is not a baby alone, but will always be accompanied by their primary caregivers, people he depends and which are subject wishing to enjoy a free society. The community practice had the effect of creating solutions to the situation that caused suffering to family members. We conclude that theories linking poverty and inability to take care of the children, they work in a similar way as minorists codes previous to Child and Adolescent Statute. Keywords: Technical Assistant Judiciary, Critical Psychology, Community Practices, Best Interests of the Child, Irregular Situation.
\end{abstract}




\title{
La Defensa Pública en una Relación de Cuidado: un Estudio de Caso
}

\begin{abstract}
Resumen: La Defensa Pública tiene lugar en la destitución del poder familiar actuando en gran medida a favor de los padres de familias pobres. El psicólogo de la Defensa Pública que actúa en los procedimientos legales se llama asistente técnico. El propósito de este artículo es discutir los conceptos pertinentes para la accíon del psicólogo en la Defensa Pública desde el lugar de asistente técnico, entendido sobre todo dentro de las políticas públicas que trabajan con las familias necesitadas de conformidad com la ley. A tal efecto, se realizó un estudio de caso con la investigación cualitativa documental en busca de posibles acciones radicales. Los datos y las acciones fueron diseñados a la luz de las teorías de desarrollo de Winnicott y el concepto de los jueces adjuntos, de Foucault. El discurso dominante en psicología mantiene la lógica de la legislación anterior en el Estatuto de los Niños y Adolescentes, en el que culpa a la familia pobre en los procesos de despido de alimentación de la familia. El asistente técnico hay figurado como un actor importante para la inclusión, en el sistema de justicia, de la comprensión que un bebé no es un bebé solo, pero siempre estará acompañado por sus cuidadores primarios, la gente que depende y que están deseando sujetos a disfrutar una sociedad libre. La práctica comunitaria produjo el efecto de crear soluciones a la situación que causó sufrimiento a los familiares. Llegamos a la conclusión de que las teorías que vinculan la pobreza y la incapacidad para cuidar de los niños trabajan de una manera similar a los códigos anteriores minoritas el Estatuto de los Niños y Adolescentes.

Palabras clave: Asistente Técnico Judicial, La Psicología Crítica, Prácticas Comunitarias, El Interés Superior del Niño, Situación Irregular.
\end{abstract}

\section{Introdução}

A ação de destituição do poder familiar está prevista no Estatuto da Criança e do Adolescente (ECA) e pode ser uma das medidas aplicáveis aos pais que, em tese, violam os direitos fundamentais de seus filhos. É o resultado de ação judicial movida pelo Ministério Público, em que este toma ciência do caso por relatos advindos de serviços ou instituições que têm obrigação de proteger o bem-estar de crianças ou de adolescentes. Durante o processo judicial sofrido pela família, é assegurado o direito ao contraditório ${ }^{1}$, em decorrência do qual cabe a atuação da Defensoria nos casos em que os pais sejam economicamente necessitados ${ }^{2}$. A ação de destituição do poder familiar pode ser precedida por outras medidas previstas no
ECA, entre elas a advertência, o acolhimento familiar ou o acolhimento institucional (Brasil, 1990).

A pobreza em nosso país, e as diversas formas de exclusão social dela decorrentes, não é um fenômeno recente. Desde os tempos do Brasil colonial, perpassando o período imperial, os períodos republicanos e a ditadura militar, vivemos em um país marcado por situações de pobreza que atingem uma larga parcela de sua população. Como efeito de sua situação econômica, as famílias pobres vivem restritas, às vezes por gerações, do provimento de necessidades básicas como alimentos, saneamento básico, educação pública acessível e de qualidade, saúde pública eficiente, emprego, transporte eficiente e outras (Nascimento, Cunha, \& Vicente, 2007; Véras, 2001).

\footnotetext{
${ }^{1}$ O termo "contraditório" aparece em nossa Constituição Federal (Brasil, 1988), no artigo 5º LV. É um conceito que diz respeito ao direito que todos os envolvidos em um processo judicial ou administrativo têm de apresentar seus argumentos e provas.

${ }^{2}$ O termo "necessitado" é o mesmo utilizado na legislação que cria a Defensoria Pública do Estado de São Paulo, Lei Complementar Estadual 988 (São Paulo, 2006). A definição do termo, contudo, fica a cargo da Deliberação CSDP nº 89/08 (São Paulo, 2008), em que se esclarece que necessitado é aquela pessoa que vive em família que: aufere renda familiar mensal não superior a três salários mínimos federais; não é proprietária, titular de aquisição, herdeira, legatária ou usufrutuária de bens móveis, imóveis ou direitos, cujos valores ultrapassem a quantia equivalente a 5.000 Unidades Fiscais do Estado de São Paulo (Ufesp); não possui recursos financeiros em aplicações ou investimentos em valor superior a 12 salários mínimos federais. Outro termo utilizado pelas normas vigentes enquanto sinônimo de necessitados é hipossuficientes. Há critérios de exceção e algumas outras variáveis que são estabelecidas pela norma. Os termos ora apresentados buscam expressar e definir a situação de pobreza vivenciada por boa parcela da população brasileira, porquanto a Lei Complementar Estadual n ${ }^{\circ}$ 988 estabelece como uma das funções da Defensoria “a erradicação da pobreza e da marginalidade” (São Paulo, 2006).
} 
No Brasil, tais restrições são frequentemente motivadoras de ações de destituição do poder familiar. Dados de um levantamento realizado em 2003 mostram que $52,0 \%$ dos abrigamentos de crianças no Brasil ocorreram em decorrência da situação de pobreza das famílias, sendo que em $24,1 \%$ dos casos, a falta de recursos materiais é diretamente citada como um dos motivos do acolhimento (Silva, 2004). Em um outro trabalho, levantou-se que de 93 processos estudados, todos eles citavam as condições de precariedade habitacional como uma das dificuldades familiares que justificariam o acolhimento institucional de crianças (Quadros, 2014). Apesar disso, o ECA tem expressa proibição de vinculação entre a falta de recursos materiais e a destituição do poder familiar (Brasil, 1990). A contradição entre a proibição e o alarmante dado da alta incidência de ações de abrigamento decorrentes da situação de pobreza resulta na formulação de que se trata de procedimentos que são resquícios históricos das legislações anteriores ao ECA, que tinham a família burguesa capitalista e economicamente ativa como modelo. Com a introdução do ECA, a família pobre passa agora ser caracterizada como família negligente e os maus-tratos passam a ser vistos como incompetências individuais, imitando-se, assim, o modelo anterior (Bernardi, 2005; Nascimento et al., 2007; Silva, 2004).

Frequentemente ocorre a atuação de profissionais da Defensoria em situações de acolhimento institucional, pedidos de destituição do poder familiar ou outras medidas aplicadas às famílias no âmbito judicial ${ }^{3}$. Em decorrência do lugar institucional que a Defensoria ocupa nos processos judiciais, ela atua, majoritariamente, em favor dos pais ${ }^{4}$. Entre os profissionais atuantes na Defensoria está o psicólogo, de modo que a atuação em processos judiciais se dá junto aos pais na qualidade do que é chamado de assistente técnico ${ }^{5}$.

A compreensão acerca dos fenômenos envoltos no sistema de justiça é tema de grande relevância, posto que o funcionamento deste sistema tem característica de modificar realidades individuais ou familiares, gerando efeitos sociais importantes (Foucault, 1975). Nesta esfera, o trabalho do psicólogo sustenta práticas que devem ser alvo de permanente discussão, dado o poder de interferência que têm sobre a vida dos seres humanos. Até o recente surgimento das Defensorias estaduais no país a partir do final da década de 1980, especialmente depois da entrada de psicólogos nestas instituições, iniciou-se a atuação dos profissionais de Psicologia na qualidade de assistente técnico em processos judiciais. No estado de São Paulo, os primeiros psicólogos ingressantes em carreira pública na Defensoria iniciaram seus trabalhos em $2010^{6}$, em um órgão interno nomeado Centro de Atendimento Multidisciplinar (CAM). O estado foi pioneiro na construção de um órgão interno com profissionais concursados de diversas disciplinas ${ }^{7}$, sendo que, dentre eles, o psicólogo é um profissional que pode atuar com atendimento direto ao público. Sobre a atividade do psicólogo enquanto assistente técnico, então, a novidade estava no fato de que era a primeira vez que se teve notícia da atuação judicial, na esfera pública, de profissionais de Psicologia atuantes em favor de cidadãos considerados necessitados.

A atuação do psicólogo na qualidade de assistente técnico, especialmente em cargos públicos estáveis e em favor da população economicamente necessitada, tem escassa bibliografia em Psicologia Jurídica brasileira (Silva, \& Costa, 2008) ${ }^{8}$. A perspectiva adotada pelas referências que existem é comumente voltada para a

\footnotetext{
${ }^{3}$ Para se ter alguma referência numérica, Gonçalves (2015) explicou que em uma unidade da Defensoria foram recebidos 155 casos novos de infância cível no período de um ano. No mesmo texto, o autor referencia que nove destes casos foram encaminhados ao profissional de Psicologia da Defensoria para desempenhar atividade de assistente técnico.

${ }^{4}$ A atuação da Defensoria se dá em favor de indivíduos necessitados, nos termos da Lei no 988/06 (São Paulo, 2006) e Deliberação CSDP n ${ }^{\circ}$ 89/08 (São Paulo, 2008). Deste modo, a atuação decorre da busca do indivíduo por defesa jurídica quando se faz necessário. A busca pela Defensoria é feita por pais cujos filhos foram acolhidos institucionalmente, majoritariamente. Daqui, temos que a principal atuação da Defensoria se faz junto aos pais.

${ }^{5}$ O Código de Processo Civil (Brasil, 2015a) estabelece que as partes (ou os cidadãos que participam de processos judiciais) poderão nomear assistente técnico em até quinze dias após nomeação de perito. Enquanto o assistente técnico é indicado pelas partes processuais, o perito é nomeado pelo juiz. O mesmo código evidencia a possibilidade de os cidadãos apresentarem estudos técnicos durante as fases iniciais do processo, antes mesmo da nomeação de um perito pelo juiz. Em razão desta última possibilidade, a compreensão aqui adotada será a de que todas as atuações profissionais que geram documentos e que são feitas junto a um cidadão que participa de um processo judicial será qualificada como atuação de assistente técnico (Gonçalves, 2015).

${ }^{6}$ A atuação dos profissionais que compõem o CAM foi regulamentada pela Deliberação CSDP no $187 / 10$ (São Paulo, 2010).

${ }^{7}$ Alguns exemplos de profissões que são ligadas ao CAM são Psicologia, serviço social, sociologia, arquitetura, engenharia, estatística, economia e ciências contábeis (São Paulo, 2006).

${ }^{8}$ Cabe explicar que a figura do psicólogo enquanto assistente técnico é recente, mas a figura do perito em cargos públicos remonta, em São Paulo, a 1985 (Silva, 2013), e encontra amplo respaldo bibliográfico.
} 
atuação do perito ou sob o viés de atuações enquanto assistentes técnicos em âmbito particular (Evangelista, Pereira, Tavares, \& Menichetti, 2000; Katayama, 2012; Liebesny, Alvim, Leonardi, \& Aoki, 2000; Silva, 2000; Suannes, 2011; Vaisberg, 2000). Na atuação particular, a contratação de um psicólogo que atue em favor de uma pessoa que é parte em um processo judicial depende, por motivos evidentes, de condição econômica que a permita. Com o estabelecimento das Defensorias e dos profissionais de Psicologia na função de assistente técnico, as famílias pobres passaram a ter acesso a esta modalidade de trabalho, sendo relevante que se pense sobre o lugar do profissional junto às famílias que acessam a Defensoria. É sobre a atuação do assistente técnico judiciário na Defensoria que o presente trabalho se debruçará.

O presente artigo tem por objetivo discutir, a partir da apresentação de um caso, algumas formas possíveis de atuação do psicólogo na Defensoria. Não se pretende esgotar a questão, mas sim iniciar o diálogo sobre rumos que a atuação prática pode tomar. Do mesmo modo, é objetivo do trabalho discutir as concepções teóricas e técnicas que emanaram do caso concreto.

\section{Método}

A perspectiva crítica na Psicologia tem raízes históricas advindas dos assim chamados Mestres da Suspeição, tal qual Marx, Nietzsche e Freud. Podemos dizer que a partir deles foi trilhada uma trajetória de evolução de ideias que vem sendo agrupada em eixos comuns dentre profissionais que se consideram críticos. Apesar das inúmeras diferenças entre autores da Perspectiva Crítica ${ }^{9}$, alguns elementos fundamentais divergem pouco: considera-se a sociedade como tendo diferenciais de poder intersetorializados, com consequências para a subjetividade humana; há a busca por uma sociedade que tenha justiça social em um mundo mais igualitário; em pesquisas, a escolha do método é feita com base em problemas relevantes em vez de se escolher somente problemas que podem ser aceitos por um determinado método; ainda na elaboração do método, compartilha-se o compromisso com a história, com a ação e a desestabilização do senso comum.

Em termos Críticos, é regra encontrarmos pesquisas cujo conhecimento é gerado pela aprendiza- gem, a partir do ponto de vista do oprimido. Com horizonte em uma sociedade que tenha justiça social em um mundo mais igualitário, a Psicologia Crítica observa a finalidade daquilo que produz para não incorrer em produção de saber que ampare relações de poder e dominação. Tal perspectiva pode adquirir concretude técnico-prática em quase todos os âmbitos de atuação da Psicologia: a clínica, a comunidade, a justiça, a educação. Neste sentido, ela não chega a se constituir uma disciplina em si, mas se encontra atrelada às formas práticas de atuação dos psicólogos (Teo, 2015).

Casos fictícios costumam ser menos intrusivos que estudos de caso. Entretanto, há que se observar se os primeiros tentam, em uma falsa alegação, tornarem-se representativos de toda a ação. Por esta razão, optou-se por realizar um estudo de caso, evitando os problemas advindos da construção de casos fictícios. Por outro lado, não se deve entender o caso estudado como forma de limitar a atuação do assistente técnico a um número restrito de práticas possíveis (Parker, 2005). Os fundamentos metodológicos nos levam, então, a uma pesquisa que conta com um certo conjunto de ações com viés ético-político claro: evitar o acolhimento institucional de crianças e fortalecer o papel dos pais como cuidadores do filho.

A pesquisa não envolveu a mera descrição dos fenômenos processuais, mas colocou a ação do assistente técnico em perspectiva em meio às relações de força presentes num processo judicial. Tal ação tem como escopo um processo intencional de trazer mudança social. Trata-se de um tipo de pesquisa de ação, porque não aponta apenas para o conhecimento da realidade, mas também identifica soluções práticas para problemas de áreas específicas (Iorio, \& Seidmann, 2013). As demandas trazidas ao judiciário pelo caso em estudo giravam em torno de questões ligadas ao desenvolvimento infantil e ao funcionamento das relações de poder entre os envolvidos. Portanto, os dados foram analisados à luz tanto de teorias desenvolvimentistas quanto de observação das relações de poder, fundamentando-se, principalmente, nas teorias winnicottianas do desenvolvimento e nos escritos foucaultianos.

O presente estudo se fez a partir de pesquisa documental e, portanto, não exigiu contato com os

\footnotetext{
${ }^{9}$ Para mais informações sobre a história e os elementos da Psicologia Crítica, ver Teo (2015).
} 
sujeitos, sendo os documentos fontes ricas de dados. A análise documental possibilitou a introdução, a reelaboração e a criação de novas formas de compreensão dos fenômenos, de modo tal que o resultado da análise superou a leitura comum, pois se fundamentou em descrições sistemáticas e suas interpretações (Gil, 2002; Rodrigues, 2015).

Os documentos analisados faziam parte de um Procedimento Administrativo (PA) da Defensoria, que se tornou um processo judicial. Trata-se de documentos de um caso atendido na Defensoria em que houve atuação do psicólogo na qualidade de assistente técnico. A pesquisa documental foi feita através de análise qualitativa dos dados coletados, observando-se o potencial de ação do psicólogo enquanto assistente técnico na Defensoria. O acesso ao PA foi concedido por meio de autorização escrita da Defensora de Infância e Juventude Cível de uma unidade da Defensoria Pública do Estado de São Paulo, garantido o anonimato dos envolvidos. Tal procedimento visou garantir a privacidade dos participantes e a proteção de suas identidades, conforme normatização vigente (Brasil, 2016a,b). Com o foco do estudo nos movimentos políticos de relações de força entre o sistema de justiça para com os cidadãos e na ação do psicólogo assistente técnico, compreende-se que o anonimato de todos os envolvidos é suficiente para evitar constrangimentos.

Em um processo de infância cível é comum que tenhamos documentos produzidos por diversas instituições: Ministério Público, Defensoria Pública, Tribunal de Justiça, equipamentos públicos de Saúde e de Assistência Social são algumas delas. A função processual e política de cada instituição é variável e não há unanimidade entre as instituições acerca dos argumentos apresentados. Os documentos pesquisados foram relatórios profissionais de psicólogos e assistentes sociais, petições realizadas por Defensores e Promotores, ofícios produzidos por profissionais das instituições, termos de declarações produzidos pelos cidadãos envolvidos, registros de atendimento na Defensoria e documentos produzidos pelos juízes. Partimos das informações documentais que foram trazidas ao judiciário pelas diversas instituições que participaram do caso para, então, realizar a análise dos dados à luz do referencial teórico da presente pesquisa.

\section{Resultados e discussão}

\section{O cenário em estudo}

Maria e José (nomes fictícios) buscaram o atendimento jurídico em uma unidade da Defensoria Pública do Estado de São Paulo. O motivo: havia poucos dias que o filho deles havia nascido e, de alta médica, não foi liberado para sair da maternidade. A saída do recém-nascido havia sido impedida por uma assistente social. A profissional produziu um documento e enviou ao sistema de justiça, com alegações de que o bebê estava em risco em razão da suspeita de que o pai era usuário de drogas, praticante de violência doméstica e de que a mãe tinha algum rebaixamento intelectual que dificultaria os cuidados do filho.

As alegações da profissional advieram de uma confusão ocorrida na maternidade. José havia, durante o registro do nascimento do filho no cartório da maternidade, brigado com sua sogra. Tanto José quanto sua sogra foram encaminhados à assistente social, momento em que a profissional coletou os relatos que embasaram a produção de seu documento. Os relatos documentais se apoiavam exclusivamente nas falas da sogra. José negou tais acusações para a assistente social da maternidade, o que foi apenas registrado.

A Defensoria compreendeu que não era juridicamente possível que a maternidade optasse, por si só, pela permanência do bebê afastado de sua família sem justificada decisão judicial ou embasado pedido do conselho tutelar. Com este teor, foi elaborado um ofício ${ }^{10}$ para a maternidade. Enquanto parte da atuação do psicólogo da Defensoria, foi tentado diálogo administrativo e interdisciplinar para a saída do bebê da maternidade, por meio de reunião e visita institucional com técnicos da maternidade, conforme se lê no relatório feito pelo assistente técnico.

O documento produzido pelo psicólogo da Defensoria explica que na maternidade os técnicos justificaram o procedimento de retenção do bebê em berçário tendo em vista um suposto risco social, ainda sob avaliação. Explicaram também que o bebê estava em um berçário específico para este fim: o de reter crianças com alta médica para avaliação social,

${ }^{10} \mathrm{O}$ ofício foi assinado pela Defensora Pública, bem como pelo psicólogo assistente técnico. Ele continha tanto referências do campo do direito quanto do campo da Psicologia. 
ainda que sem decisão judicial. Especialmente acerca do filho de Maria e José, havia sido produzido um relatório com as falas da avó do bebê que fora enviado para a Vara da Infância para que o juiz decidisse sobre o acolhimento ou não do bebê. A maternidade não se abriu, portanto, para a possibilidade administrativa de alta daquela criança.

Diante disso, uma dupla atuação da Defensoria foi iniciada. De um lado, a Defensora do caso produziu um pedido judicial de liberdade do bebê através de um procedimento jurídico chamado de Habeas Corpus $^{11}$. De outro lado, o psicólogo procurou por alternativas familiares e comunitárias de cuidados do bebê, tanto para garantir seu desenvolvimento quanto com a finalidade de produzir documentos técnicos que esclarecessem a realidade familiar para o sistema de justiça.

Dos registros documentais do psicólogo assistente técnico, viu-se que foi realizada visita domiciliar para parentes de Maria e para vizinhos do casal. A coleta de dados encontrou, nestas fontes de informação, uma nova história bastante diversa daquela contada na maternidade pela mãe de Maria. As pessoas que se interessaram em contar a história do casal relatavam que Maria e José eram pessoas com bom relacionamento, sem histórico de violência entre si. O relacionamento entre o casal e a comunidade era pacífico, sem relatos de conflitos ou problemas. Uma vizinha relatou que deixava, sempre que precisava, sua filha com o casal por longos períodos, sem que houvesse relatos de inadequações nos cuidados. Do mesmo modo, não havia nenhuma suspeita de recente uso de drogas pelo pai da criança, considerando-se um período aproximado de dois anos. Os relatos foram coletados em termos de declarações, assinados pelos cidadãos que vivenciaram o cotidiano comunitário do casal. Familiares e pessoas da comunidade registraram apoio ao casal e subscreveram outros termos de que se comprometiam em auxiliar nos cuidados da criança recém-nascida, caso necessário.

No encontro entre as demandas processuais e o trabalho junto à comunidade, o relatório produ- zido na qualidade de assistente técnico foi entregue à Defensora. O pedido judicial de Habeas Corpus já havia sido feito, entretanto o documento psicológico fora incluído em momento posterior no processo ${ }^{12}$. A sentença do juiz explicava que o relato da avó, especialmente contraditado pelo pai e pelo pedido da Defensoria, não era suficiente para justificar o abrigamento do bebê, de modo tal que, assim que a maternidade entendesse que o bebê estava de alta médica, ele deveria sair da maternidade.

Com a saída do bebê da maternidade, agora a preocupação se voltava para a garantia de cuidados específicos para os pais e para o bebê no sentido de possibilitar o desenvolvimento saudável do filho (Winnicott, 1971) ${ }^{13}$. Nas soluções comunitárias, alguns procedimentos foram tomados. O contato do psicólogo da Defensoria com a família ocorreu de forma continuada. Houve a busca por equipamentos públicos capazes de ofertar políticas de cuidado voltadas ao desenvolvimento infantil e à permanência do bebê no núcleo familiar. O Centro de Saúde (CS) foi contatado para uma reunião e a mãe do bebê foi encaminhada ao Centro de Referência de Assistência Social (CRAS) mais próximo de sua casa para obter informações acerca de benefícios socioassistenciais que pudessem ser acessados pela família.

O medo que os pais passaram a ter de os representantes das políticas públicas ainda quererem afastar o bebê da família foi notado na Defensoria: os pais telefonavam com frequência para perguntar se poderiam receber, sem temor, a visita dos profissionais do CS em sua casa. O psicólogo da Defensoria, ao se aproximar do Centro de Saúde após a decisão judicial, explicou para este equipamento público a história do bebê e sua família. Com o olhar voltado para a nova história apresentada, surgiram sugestões de atuações de cuidado do núcleo familiar que levavam em conta os temores que a família apresentava. Entre eles, a visita domiciliar continuada e o fortalecimento do vínculo entre a família e os profissionais seriam prioridades. A partir destas intervenções da Defensoria, com reuniões, contatos telefônicos e visita domiciliar,

\footnotetext{
${ }^{11}$ Trata-se de um dispositivo jurídico previsto pela Constituição Federal (Brasil, 1988). O instrumento deve ser concedido "sempre que alguém sofrer ou se achar ameaçado de sofrer violência ou coação em sua liberdade de locomoção, por ilegalidade ou abuso de poder”. ${ }^{12}$ Apesar de o documento ter sido incluído no processo apenas após a sentença do juiz, o relatório produziu efeitos de apoiar as manifestações posteriores que foram feitas pelos órgãos envolvidos.

${ }^{13}$ A obra de Winnicott será citada pela classificação estabelecida por Hjulmand $(1999,2007)$, dado que ela será usada na publicação das obras completas de Winnicott, tal como informou Abram (2008).
} 
iniciou-se o estabelecimento de uma relação dialógica e de confiança entre os pais e os serviços públicos que os acompanhavam.

Na atuação conjunta da Defensoria e do Centro de Saúde, tentou-se vencer o elemento discursivo não tanto pelo combate ao medo criado, mas pela oferta de cuidados seguros e sustentáveis. Na opinião dos técnicos do Centro de Saúde, de fato a mãe tinha algum nível de rebaixamento intelectual, mas era insuficiente para significar prejuízos ao desenvolvimento da criança. Além das ações de orientação e esclarecimento, houve o início dos trabalhos de equipe de saúde mental para avaliação e cuidados da mãe. Tudo isto foi posto em marcha. $O$ bebê se desenvolveu, até a finalização deste texto, dentro do esperado para a sua idade.

Nesta toada, a Defensoria ainda receberia o contato do Centro de Referência Especializado de Assistência Social (Creas). Os contatos, que se encontram eletronicamente documentados, davam conta de mais procedimentos da maternidade após alta do bebê. Depois da decisão judicial que culminou com a saída do bebê da maternidade, a equipe técnica da maternidade enviou seu relatório com os relatos da avó ao Creas, pedindo a apuração das violações de direitos que supostamente estariam sendo praticadas pelo casal Maria e José. O Creas, entretanto, acabou por compreender que o acompanhamento sistemático local do CS e do CRAS seria suficiente para garantir que o bebê se desenvolvesse sem violações em seus direitos.

\section{Reflexões Analíticas}

A perspectiva crítica da Psicologia tem como princípio a participação ativa da comunidade, cujo trabalho advém da concepção de que os sujeitos que vivenciam os problemas são capazes de se tornar conhecedores de seus sofrimentos para, então, serem participantes ativos na construção dos enfrentamentos e soluções dos problemas. O trabalho crítico faz movimento de resistência às práticas tradicionais da Psicologia, já que tem

[...] o intuito de construir uma análise ante as práticas dominantes e legitimadas pela Psicologia e buscar as contradições das ideias que são propagadas como naturais. Trata-se de um movimento dialético que não visa a dar explicações de caráter apenas subjetivo, mas a levantar as contradições e a revelar as táticas políticas e ideológicas obscurecidas que permeiam a prática do psicólogo (Ribeiro, \& Guzzo, 2014, p. 87).

A referência radical, contra a qual foi feito o enfrentamento, é a violação do direito básico de convivência familiar, previsto pelo ECA. O embasamento teórico que sustentou a ação foi a teoria de desenvolvimento de Winnicott, dada a importância de se compreender o desenvolvimento humano saudável para que fosse possível a proposição de ações que o garantisse.

O desenvolvimento de um bebê saudável o leva à independência, à autonomia. Um indivíduo saudável será permeado por medos, conflitos, dúvidas, frustrações, tanto quanto sentimentos positivos. Neste sentido, saúde não é sinônimo de mera ausência de doença psiconeurótica. O vínculo afetivo figura como um componente central para a sustentação de um ambiente que propicie o desenvolvimento do bebê até que atinja à independência, o que, portanto, o tornará um indivíduo saudável. A sustentação ambiental faz com que o bebê seja capaz de realizar seu desenvolvimento pessoal, tendo como resultado a continuidade da existência e a autonomia (Winnicott, 1971).

No sentido ora apresentado, o bebê saudável é aquele que se encontra em desenvolvimento, caminhando desde a dependência absoluta até a independência relativa. $\mathrm{O}$ vínculo afetivo, por ser elemento central na criação de um ambiente que propicie tal desenvolvimento, é um sólido motivo para a compreensão de que a intervenção do Estado não deva incidir diretamente sobre o afastamento da criança de seu lar, ainda mais se considerarmos que os efeitos do afastamento podem ser graves e irreversíveis (Bowlby, 1976; Winnicott, 1949, 1950).

A compreensão winnicottiana de desenvolvimento saudável, pensado desde a dependência absoluta até a independência relativa, pode ser utilizada como base para a construção de um conceito de democracia (Winnicott, 1950, 1971). Tal conceito envolve uma concepção flutuante em relação ao que a sociedade compreende como sendo um sujeito maduro e também a noção de liberdade para a criação de filhos. Uma sábia política de cuidados interfere pouco na realidade familiar, em nome da garantia da liberdade de diferenças entre seres humanos (Winnicott, 1950). Uma prática que se ocupa com o cuidado efetivo de crianças, portanto, se ocupa 
menos com fazer interferências sobre os sujeitos, a partir do uso do aparato coercivo da justiça, do que com ampliar o potencial de todos para transformar realidades difíceis em ambientes possíveis ao desenvolvimento saudável e livre.

De modo análogo, a concepção de cuidado em Foucault perpassa a permissividade que deve existir em um sujeito ao deixar o outro ser livre, em vez de se impor e tentar controlar a realidade do outro (Foucault, 2012; Mizrahi, 2008). Nesta íntima interface entre a teoria winnicottiana e foucaultiana, sob a perspectiva da liberdade e do cuidado, temos o resultado político da atuação do psicólogo da Defensoria: a busca pela garantia de que os pais possam cuidar de seus filhos de um modo tal que seja favorecido o desenvolvimento infantil rumo à independência e à liberdade.

Num sentido contrário, o sistema de justiça brasileiro opera, com grande frequência, a sistematização de um fenômeno chamado de acolhimento institucional de bebês direto da maternidade (Brasil, 2015b; Gonçalves, 2015). O fenômeno tem seu funcionamento semelhante ao ocorrido no caso de Maria e de José: a maternidade envia relatórios ao sistema de justiça que, por sua vez, determina o acolhimento institucional da criança ${ }^{14}$.

A atuação da Defensoria, realizada contra o acolhimento institucional do filho de Maria e de José, oportunizou aos pais afastar os tentáculos do poder judiciário sobre o núcleo familiar através de atuação interdisciplinar. A realidade e a história familiar, quando esclarecidos ao sistema de justiça, fez saltar aos olhos a compreensão de que a atuação dos profissionais da maternidade se comparou ao que Foucault (1975) chamou de juízes anexos ${ }^{15}$. Imbuídos de um poder de decisão sobre a retenção de bebês, justificado sob pretensa legitimação de um discurso exclusivamente pautado no argumento da proteção de crianças, o afastamento deles em relação aos seus respectivos núcleos familiares ocorreu estendendo o braço técnico do sistema de justiça à maternidade. Para além do caso que agora temos contato, quantos outros casos semelhantes não são ou foram vividos sem que se permitisse aos pais a chance de cuidarem de seus filhos? Não é possível se obter tal resposta com precisão.

O superior interesse da criança tem sido o viés dominante na atuação dos psicólogos (Suannes, 2011). A nomeação do que é negligência, violência ou abuso fica a cargo de profissionais cientistas que funcionam como juízes anexos (Foucault, 1975) e, deste modo, são eles que passam a também nomear o que é o interesse da criança. A nomeação do interesse da criança foi feita, no caso concreto, de forma a gerar conflito com o interesse dos pais em permanecer com seu filho e, de outro ângulo, de forma a ignorar que é parte do interesse da criança, nos moldes da legislação vigente, a convivência com sua família de origem. Portanto, compreendeu-se o interesse da criança de modo similar às compreensões advindas de legislações anteriores ao ECA, caracterizadas como práticas minoristas. Pais e filhos, distanciados pelo discurso científico do interesse da criança, agora podem ser fisicamente afastados por instituições de poder tal qual o sistema de justiça.

Contra essa concepção, a atuação prática do psicólogo na qualidade de assistente técnico se mostrou como importante instrumento para a inserção de uma compreensão diversa da dominante no sistema de justiça, seja pelo diálogo técnico com a figura do Defensor Público ou por produção documental no processo ${ }^{16}$. Não se trata de dizer que os direitos de crianças e de adolescentes podem ser postos de lado, mas sim de compreender que um bebê não é um bebê sozinho, será sempre acompanhado de seus pais ou principais cuidadores, pessoas de quem ele depende (Winnicott, 1958). Portanto, ele estará acompanhado de outras pessoas que também são sujeitos que pretendem desfrutar de uma sociedade livre, que interve-

\footnotetext{
${ }^{14}$ Em casos como este, é frequente que a mãe se encontre ainda internada. Portanto, não é ouvida pelo sistema de justiça e, tampouco, consegue acessar a Defensoria. Também é comum que os familiares desconheçam a possibilidade de busca por defesa técnica (Gonçalves, 2015).

${ }^{15}$ É profícua a discussão sobre o biopoder e o moderno papel dos profissionais de equipamentos de saúde pública sobre a vida dos sujeitos. Tal análise, entretanto, extrapolaria o campo de análise aqui pretendido, qual seja o de conhecer os mecanismos de poder que envolvem o sistema de justiça e a atuação radical do assistente técnico contra práticas hegemônicas neste sistema.

${ }^{16}$ No caso aqui descrito, a decisão judicial adveio da defesa apresentada pelo Defensor Público antes de o psicólogo assistente técnico ter entregue seu trabalho escrito. Apesar disso, chamamos a atenção para a atuação do psicólogo na formulação do ofício entregue à maternidade antes mesmo da existência do processo, documento que continha a visão técnica do psicólogo sobre a situação familiar. Durante o processo, o relatório psicológico entregue gerou efeitos na garantia da defesa técnica integral, dando voz à história familiar e auxiliando na posterior manutenção da decisão de permanência do bebê com os pais.
} 
nha mais pelo desenvolvimento pessoal do que pela culpabilização individual (Nascimento et al., 2007; Winnicott, 1950). Sob esta ótica, a intervenção interdisciplinar e interinstitucional realizada pelo assistente técnico possibilitou, para além da visibilidade para a capacidade dos pais em serem cuidadores, potencializar as ações da família no começo de sua vida com o bebê, considerando-se os medos e as inseguranças advindas de um iminente processo judicial, cujo efeito poderia separar pais e criança.

\section{Considerações finais}

Da prática do psicólogo na qualidade de assistente técnico, foi possível depreender que há profícuo campo de estudos em um campo apenas recentemente inaugurado. Aqui temos um ponto de partida para a atuação do assistente técnico a partir da discussão de concepções técnicas que sustentem sua prática, especialmente em oposição às práticas hegemônicas. Isto porque práticas dominantes consideram a pobreza como um dos elementos capazes de afastar crianças do lar e, por tal razão, funcionam de modo similar aos códigos minoristas anteriores ao ECA, operando a manutenção do princípio da situação irregular (Iorio, \& Seidmann, 2013; Nascimento et al., 2007). Fundamentando a atuação do assistente técnico na intervenção sobre a realidade, conclui-se que formas criativas de intervenção sobre realidades muito difíceis precisam emanar a partir da concepção de que a constru- ção de uma sociedade melhor depende de os sujeitos serem respeitados em suas diferenças.

O presente estudo traz à tona a necessidade de se estudar mais sobre o papel do assistente técnico judicial e também sobre o interesse da criança do ponto de vista da Psicologia neste novo lugar de atuação, posto que aqui a análise restringiu-se a um caso particular. A realização de novos estudos que visam compreender como é feita a construção do interesse da criança nos processos judiciais e como ele pode, por vezes, ser um mecanismo que resulta no desmembramento das famílias é fundamental para sistematizar práticas críticas quanto à produção psicológica no contexto judiciário.

Neste sentido, é relevante que o psicólogo assistente técnico judiciário que atua na Defensoria trabalhe com concepções não culpabilizadoras dos usuários atendidos. A concepção não culpabilizadora fez com que políticas públicas funcionassem de modo a permitir o saudável desenvolvimento da criança. Foi a prática comunitária, local, realizada por sujeitos implicados com o problema, que produziu o efeito de criar soluções para a situação que gerou sofrimento aos membros de uma família. Não somente por conta de a organização local se movimentar no sentido do cuidado da família e do bebê, mas também por conta de a comunidade ter se empenhado em materializar a resistência contra o sistema por meio de documentos capazes de subsidiar a atuação do psicólogo e do Defensor Público.

\section{Referências}

Abram, J. (2008). Donald Woods Winnicott (1896-1971): a brief introduction. The International Journal of Psychoanalysis, 89(6), 1189-1217. https://doi.org/10.1111/j.1745-8315.2008.00088.x

Bernardi, D. C. F. (2005). Concepções de infância em relatórios psicológicos judiciais (Dissertação de mestrado). Pontifícia Universidade Católica de São Paulo, São Paulo, SP.

Bowlby, J. (1976). Cuidados maternos e saúde mental (Vera Lúcia Batista Souza; Irene Rizzini, trads.). São Paulo, SP: Martins Fontes.

Brasil. (1988). Constituição da República Federativa do Brasil de 1988. Diário Oficial da União. 5 out. 1988.

Brasil. (1990). Lei No 8.069, de 13 de julho de 1990. Dispõe sobre o Estatuto da Criança e do Adolescente e dá outras providências. Diário Oficial da União. 16 jul. 1990.

Brasil. (2015). Lei no 13.105, de 16 de março de 2015. Código de Processo Civil. Diário Oficial da União. 17 mar. 2015.

Brasil. (2016b). Ministério da Saúde. Conselho Nacional de Saúde. Resolução No 196, de 10 de outubro de 1996. Aprova diretrizes e normas regulamentadoras de pesquisas envolvendo seres humanos. Diário Oficial da União. 16 out. 1996 
Brasil. (2016a). Ministério da Saúde. Conselho Nacional de Saúde. Resolução No 510, de 7 de abril de 2016. Dispõe sobre as normas aplicáveis a pesquisas em Ciências Humanas e Sociais cujos procedimentos metodológicos envolvam a utilização de dados diretamente obtidos com os participantes ou de informações identificáveis ou que possam acarretar riscos maiores do que os existentes na vida cotidiana. Diário Oficial da União. 24 maio 2016

Brasil (2015b). Ministério da Saúde. Secretaria de Atenção à Saúde. Nota técnica conjunta No 001 - SAS e SGEP. Diretrizes e fluxograma para a atenção integral à saúde das mulheres e das adolescentes em situação de rua e/ou usuárias de crack/outras drogas e seus filhos recém-nascidos. Recuperado de http://portalsaude.saude. gov.br/images/pdf/2015/outubro/08/Nota-t--cnica--diretrizes-e-fluxograma-mulher-sit-rua.pdf

Evangelista, R., Pereira, S. S., Tavares, A. P. V., \& Menichetti, D. (2000). Relato da construção de trabalho psicológico no Ministério Público do Estado de São Paulo. In: Anais do 3o. Congresso Ibero-americano de Psicologia Jurídica (pp. 317-319). São Paulo, SP.

Foucault, M. (1975). Vigiar e punir (Pedro Elói Duarte, trad.). Lisboa: Edições 70.

Foucault, M. (2012). A ética do cuidado de si como prática da liberdade. In M. B. Motta (Org.). Ética, sexualidade, política (3a ed, Vol. 5; E. Monteiro ,\& I. A. D. Barbosa, trads.). Rio de Janeiro, RJ: Forense Universitária.

Gil, A. C. (2002). Como elaborar projetos de pesquisa. São Paulo, SP: Atlas.

Gonçalves, M. A. B. (2015). Assistente técnico judiciário na Defensoria Pública: suporte da teoria de Winnicott. (Dissertação de mestrado). Pontifícia Universidade Católica de Campinas, Campinas, SP.

Hjulmand, K. (1999). Lista completa das publicações de D. W. Winnicott. Natureza Humana, 1(2), 459-517. Recuperado de http://pepsic.bvsalud.org/scielo.php?script=sci_arttext\&pid=S1517-24301999000200012

Hjulmand, K. (2007). D. W. Winnicott: bibliography: chronological and alphabetical lists. In Jan Abram, The language of Winnicott: a dictionary of Winnicott's use of words (2a ed, pp. 363-435). London: Karnac.

Iorio, J. D., \& Seidmann, S. (2013). Why are they confined? The knowledge and practices of institutionalized children. Annual Review of Critical Psychology, 10, 62-78.

Katayama, E. (2012). Questões éticas: psicólogo(a) parecerista, perito(a) e assistente técnico(a). Jornal Psi, 171. Recuperado de http://www.crpsp.org.br/portal/comunicacao/jornal_crp/171/frames/fr_questoes_ eticas.aspx

Liebesny, B., Alvim, R. C., Leonardi, A. I., \& Aoki, M. (2000). O trabalho da comissão de ética na interface com o jurídico. In Anais do 3o. Congresso Ibero-americano de Psicologia Jurídica (pp. 63-64). São Paulo, SP.

Mizrahi, B. G. (2008). Um contraponto ao biopoder e ao desamparo no contexto contemporâneo: reflexões winnicottianas. (Tese de doutorado). Pontifícia Universidade Católica do Rio de Janeiro, Rio de Janeiro. RJ.

Nascimento, M. L., Cunha, F. L., \& Vicente, L. M. D. (2007). A desqualificação da família pobre como prática de criminalização da pobreza. Revista Psicologia Política, 7(14). Recuperado de http://pepsic.bvsalud.org/scielo. php?script=sci_arttext\&pid=S1519-549X2007000200006

Parker, I. (2005). Qualitative psychology: introducing radical research. Glasgow: Bell and Bain.

Quadros, L. F. (2014). Ações de destituição do poder familiar e sua relação com a ausência de moradia adequada. Revista da Defensoria Pública: Edição especial de Habitação e Urbanismo, pp.126-140. Recuperado de http:// www.defensoria.sp.def.br/dpesp/repositorio/28/Revista\%20NHUrb.pdf

Ribeiro, M. E., \& Guzzo, R. S. L. (2014). Psicologia no Sistema Único de Assistência Social (SUAS): reflexões críticas sobre ações e dilemas profissionais. Pesquisas e Práticas Psicossociais, 9(1), 83-96. Recuperado de http://seer.ufsj. edu.br/index.php/revista_ppp/article/view/837

Rodrigues, M. F. (2015). Rede de proteção à criança e ao adolescente na Assistência Social em Campinas: o real, o necessário e o possível. Campinas, SP: PUC - Campinas.

São Paulo (Estado) (2006). Lei Complementar No 988, de 9 de janeiro de 2006. Organiza a Defensoria Pública do Estado, institui o regime jurídico da carreira de Defensor Público do Estado. Recuperado de http://www.al.sp. gov.br/repositorio/legislacao/lei.complementar/2006/lei.complementar-988-09.01.2006.html 
São Paulo (Estado). (2008). Conselho Superior da Defensoria Pública. Deliberação CSDP nº 89, de 8 de agosto de 2008. Regulamenta as hipóteses de denegação de atendimento. Recuperado de http://www.defensoria.sp.gov. $\mathrm{br} /$ dpesp/Conteudos/Materia/MateriaMostra.aspx?idItem=2485

São Paulo (Estado). (2010). Conselho Superior da Defensoria Pública. Deliberação CSDP $\mathrm{n}^{\circ} 187$, de 12 de agosto de 2010. Disciplina a estrutura e funcionamento dos Centros de Atendimento Multidisciplinar. Recuperado de http://www.defensoria.sp.gov.br/dpesp/Repositorio/0/Documentos/Deliberacao_ CSDP_187.pdf

Silva, E. R. A. (2004). O perfil da criança e do adolescente nos abrigos pesquisados. In E. R. A. Silva (Org.), O direito à convivência familiar e comunitária: os abrigos para crianças e adolescentes no Brasil (pp. 41-70). Brasília, DF: IPEA / CONANDA.

Silva, E. Z. M. (2000). O estudo psicológico: uma contribuição para o entendimento do direito de família. Anais do III Congresso Ibero-americano de Psicologia Jurídica, 143-145.

Silva, E. Z. M. (2013). Psicologia jurídica: um percurso nas varas de família do tribunal de justiça do estado de São Paulo. Psicologia: Ciência e Profissão, 33(4), 902-917. https://doi.org/10.1590/S1414-98932013000400010

Silva, M., \& Costa, G. (2008). O papel dos assistentes técnicos nos processos judiciais. In Anais do 3o. Congresso Ibero-americano de Psicologia Jurídica (pp. 258-261). São Paulo, SP.

Suannes, C. A. M. (2011). A sombra da mãe: psicanálise e vara de família. São Paulo, SP: Casa do Psicólogo.

Teo, T. (2015). Critical psychology: a geography of intellectual engagement and resistance. American Psychologist, 70(3), 243-254. https://doi.org/10.1037/a0038727

Vaisberg, T. M. J. A. (2000). A disputa de guarda sob um olhar winnicottiano. In Anais do3o. Congresso Ibero-americano de Psicologia Jurídica (pp. 367-370). São Paulo, SP.

Véras, M. P. B. (2001). Exclusão social: um problema brasileiro de 500 anos. In B. Sawaia (Org.), As artimanhas da exclusão: análise psicossocial e ética da desigualdade social (2a ed, pp. 27-50). Petrópolis, RJ: Vozes.

Winnicott, D. W. (1950). Algumas reflexões sobre o significado da palavra "Democracia”. In D. W. Winnicott, Tudo começa em casa (Paulo Sandler, trad.; pp. 249-271). São Paulo, SP: Martins Fontes.

Winnicott, D. W. (1958). A preocupação materna primária. In D. W. Winnicott, Da pediatria à psicanálise: obras escolhidas (Davy Bogomoletz, trad.; pp. 399-405). Rio de Janeiro, RJ: Imago.

Winnicott, D. W. (1949). O bebê como organização em marcha. In D. W. Winnicott, A criança e seu mundo (p. 26-30). Rio de Janeiro: Zahar. 1982.

Winnicott, D. W. (1971). O conceito de indivíduo saudável. In D. W. Winnicott, Tudo começa em casa (Paulo Sandler, trad.; pp. 3-22). São Paulo, SP: Martins Fontes.

Marcos Antonio Barbieri Gonçalves

Doutorando em Psicologia como Ciência e Profissão pela Pontifícia Universidade Católica de Campinas, Campinas - SP. Brasil.

E-mail: psicologo@marcosgoncalves.com

\section{Raquel Souza Lobo Guzzo}

Doutora em Psicologia Escolar e do Desenvolvimento Humano pela Universidade de São Paulo, São Paulo - SP. Pós-doutora em Estudos Comunitários e Prevenção pela University of Rochester, New York. USA. Docente da Pontifícia Universidade Católica de Campinas, Campinas - SP. Brasil.

E-mail: rslguzzo@gmail.com

Endereço para envio de correspondência:

Defensoria Pública do Estado de São Paulo, Regional de Campinas, Centro de Atendimento Multidisciplinar (CAM). Av. Francisco Xavier de Arruda Camargo, 300, Bloco C, Salas 20/21. Jd. Santana. CEP: 13088-901.

Campinas - SP. Brasil. 
Recebido 24/05/2016

Aprovado 12/12/2016

Received 05/24/2016

Approved 12/12/2016

Recibido $24 / 05 / 2016$

Aceptado 12/12/2016

Como citar: Gonçalves, M. A. B., \& Guzzo, R. S. L. (2017). A defensoria pública e cuidados em uma Relação de Cuidado: Um Estudo de Caso. Psicologia: Ciência e Profissão, 37(1): 236-247. https://doi.org/10.1590/1982-37030001772016

How to cite: Gonçalves, M. A. B., \& Guzzo, R. S. L. (2017). The public defender in a care relationship: a case study. Psicologia: Ciência e Profissão, 37(1): 236-247. https:// doi.org/10.1590/1982-37030001772016

Cómo citar: Gonçalves, M. A. B., \& Guzzo, R. S. L. (2017). La defensa pública en una relación de cuidado: un estudio de caso. Psicologia: Ciência e Profissão, 37(1): 236-247. https://doi.org/10.1590/1982-37030001772016 